\title{
Simultaneous behavioral and neural (cochlear nucleus) measurement during signal detection in the rabbit
}

\author{
RONALD E. KETTNER, ROBERT V. SHANNON, THANH M. NGUYEN, \\ and RICHARD F. THOMPSON \\ Department of Psychobiology and School of Social Sciences \\ University of California, Irvine, California 92717
}

\begin{abstract}
Classical conditioning of the rabbit nictitating membrane (NM) response was adapted as a model system for simultaneous measurement of behavioral and neural responses in auditory signal detection. Animals were trained to a 36-dB spectral-level white-noise CS paired with a corneal airpuff US. The CS intensity was then reduced to threshold, using a modified staircase procedure, and responses on detect and nondetect trials were compared for the same stimulus intensities. At threshold, the behavioral NM response was dichotomous, being present on detect trials and completely absent on nondetect trials. In marked contrast, evoked neural unit activity to the CS recorded from the anteroventral cochlear nucleus was clearly present and identical on both detect and nondetect trials, suggesting that the detection "decision" is made more centrally than the cochlear nucleus.
\end{abstract}

Current psychophysical theory in hearing depends on assumed neurophysiological processes in the auditory nervous system (Green \& Luce, 1974; Green \& Swets, 1966; Luce \& Green, 1972, 1978; McGill, 1967; Shevell, 1979; Swets, 1964; Wandell, 1976). Most of the neuronal information available is from electrophysiological studies of acute, anesthetized animals. It is advantageous to have an animal preparation in which both behavioral "judgments" and neurophysiological processes can be studied simultaneously. In this paper, we report on the development of such a preparation for the study of signal detection.

In earlier work, we have utilized classical conditioning of the rabbit nictitating membrane (NM) response to a tone CS, using a corneal airpuff US, initially developed by Gormezano, Schneiderman, Deaux, and Fuentes (1962), as a model system for analysis of brain substrates of learning (Thompson, Berger, Cegavske, Patterson, Roemer, Teyler, \& Young, 1976). This preparation has unique advantages for the simultaneous study of behavioral and

Supported in part by research grants from the National Science Foundation (BMS 75-00453), the National Institutes of Health (NS 23368), and the McKnight Foundation, and a predoctoral grant from the Focused Research Program in Perception and Higher Mental Processes through the School of Social Sciences. We thank Patrick Gomez, Susan Kay, Walter Thistlewaite, and Jann Lincoln for assistance. R. V. Shannon's current address is Coleman Laboratory, 863 HSE, University of California, San Francisco, California 94143 . R. F. Thompson's present address is Department of Psychology, Stanford University, Stanford, California 94305. neuronal processes in the context of auditory psychophysical discrimination behavior. In particular, the rabbit adapts well to restraint that completely immobilizes the head, permitting precise stimulus control and recording of single-neuron activity. Furthermore, the learned behavioral response of extension of the NM is quantifiable-the latency, amplitude, and time course of the NM response are easily and accurately measured. Behaviorally, the conditioned NM response does not exhibit sensitization or pseudoconditioning and has a virtually negligible spontaneous response rate (Gormezano, 1966, 1972). All these characteristics seem especially helpful for analysis of the neuronal substrates of signal detection behavior.

\section{METHODS}

\section{Training}

Behavioral data are reported from a total of 13 New Zealand White rabbits, weighing from 2.2 to $2.8 \mathrm{~kg}$, all free from ear infection. In overview, the rabbits were trained to respond at threshold in three stages. They were first classically conditioned to respond to a moderate-intensity (36-dB spectral level) whitenoise stimulus. They were then overtrained to insure that learning had reached asymptote. Finally, the auditory stimulus was slowly reduced in intensity to threshold, using a modified staircase procedure (Cornsweet, 1962; Levitt, 1971). The rabbits were maintained at behavioral threshold for from 7 to 10 days.

The nictitating membrane (NM) was classically conditioned using a procedure developed by Gormezano et al. (1962). The conditioned stimulus (CS) was a 350-msec white-noise burst. It was paired with the unconditioned stimulus (US), a 100-msec airpuff delivered to the rabbits' cornea, which began $250 \mathrm{msec}$ after CS onset and coterminated with the US. On paired trials, a conditioned response (CR) was scored if the NM moved more than 
$.5 \mathrm{~mm}$ after CS onset and before US onset. On CS-alone trials, a $C R$ was scored if the $\mathrm{NM}$ moved more than $.5 \mathrm{~mm}$ after $\mathrm{CS}$ onset, but no later than 550 msec after CS onset. This was done to allow for long-latency CRs at auditory threshold. The actual amplitude of the NM response was measured and recorded on every trial for subsequent analysis. Spontaneous movement during a trial was defined as NM movement of $.5 \mathrm{~mm}$ or more during the 200 -msec pre-CS period. Trials with spontaneous movement were excluded from analyses that compared detect and nondetect trials, but were used as a measure of the frequency of false alarms.

The rabbits were trained with the following schedule. During the first day, the rabbits were placed in the apparatus to accustom them to the experimental situation but were given no auditory or airpuff stimulation. The following day, the animals were conditioned to a white-noise CS of $36 \mathrm{~dB}$ presented every $50 \mathrm{sec}$ for 100 trials. The US was paired randomly with the CS on $75 \%$ of the trials, and the CS was presented alone on the remaining $25 \%$ of the trials. Conditioning was continued until the animal had met our learning criteria by making eight CRs on any nine consecutive trials. After the animal had reached criterion, it was overtrained until it had responded with a CR on $80 \%$ of the trials on 2 consecutive days. The intertrial interval was then reduced to $30 \mathrm{sec}$, and the number of trials was increased to 140 . When the animal was again responding at $80 \%$ for an entire session, we began to reduce the CS intensity to auditory threshold.

The CS intensity was reduced using a modified staircase procedure. This consisted of reducing the CS intensity by $2 \mathrm{~dB}$ if the animal made four CRs in a row, and increasing the CS intensity by $2 \mathrm{~dB}$ if the animal missed four CRs in a row. Our modification was to limit reductions in CS intensity to a total of no more than $10 \mathrm{~dB}$ per session until threshold had been reached. This was done to lessen the effects of generalization decrement due to rapid decreases in CS intensity. By definition, "threshold was reached" when the rabbit had missed four CRs in a row, and the "threshold level of a session" was defined to be $2 \mathrm{~dB}$ above the lowest level reached using this staircase procedure. The staircase procedure asymptotes at $50 \%$ responding and thus yields the more traditional definition of threshold. After threshold had been reached, the number of CS-US paired trials was reduced from $75 \%$ to $25 \%$ in two $25 \%$ steps-a $25 \%$ reduction during each of the following two sessions. Each of these sessions was initiated with a $C S$ intensity $6 \mathrm{~dB}$ above the previous day's threshold. The reduction in CS-US paired trials was necessary because we wished to study detection behavior free from the confounding influence of the US.

Under these final conditions, we studied detection behavior. Each day, the CS intensity was initiated $6 \mathrm{~dB}$ above the previous day's threshold, the number of CS-US paired trials was set at $25 \%$, leaving $75 \%$ CS-alone trials, and the staircase method was continued for the entire session. One slight modification was made under these final conditions. Only CS-alone trials were examined in the staircase procedure. CS-US paired trials were ignored because the US could have obscured long-latency CRs at these low CS intensities, making threshold measurements artificially high. These conditions were maintained for several sessions.

\section{Apparatus}

At the start of training, the rabbit was placed in a special Plexiglas restrainer which immobilized its pinnae. A headstage was bolted to the rabbit's skull, using the output plug and nut that had been cemented to the skull during surgery. The headstage housed a minitorque potentiometer and an airpuff nozzle for recording NM movement and for the delivery of airpuffs. Auditory stimuli were presented via a midrange horn positioned immediately over the rabbit's ear openings at a distance of $9 \mathrm{~cm}$. Both the restrainer and the horn were bolted in place during the experiment. The auditory apparatus is discussed in more detail in the next section.

The airpuff was delivered by a nozzle secured to the rabbit's headstage. It was positioned $1 \mathrm{~cm}$ from the cornea and directed at the pupil of the eye. Compressed air pressurized at $140 \mathrm{~g} / \mathrm{cm}^{2}$ was gated by a dc electric valve (Skinnez) with an orifice diameter of $1.6 \mathrm{~mm}$. The air then traveled via a Tygon tube (i.d. $6.4 \mathrm{~mm}$ ) to the puff nozzle (i.d. $3.2 \mathrm{~mm}$ ). The valve was activated early to allow for transit time. The airpuff onset time refers to the actual arrival time of the airpuff at the cornea.

Movements of the NM were measured with a minitorque potentiometer attached to the rabbit's headstage. NM movement pulled a string which pulled a counterbalanced lever attached to the potentiometer. The eyelids were held open and out of the way with eye clips. NM voltage changes were recorded on both polygraph paper and on magnetic tape using a Crown-Vetter 8-track tape recorder. An FM plug-in was used to record the low-frequency NM signal. On a separate channel, synch pulses were simultaneously recorded for use in computer analysis. These included a pre-CS pulse marking trial initiation, a CS pulse marking whitenoise onset, and a US pulse marking airpuff onset.

Single- and multiple-unit neural activity was first amplified by FET transistors housed on the rabbit headstage to reduce the impedance of the neural signs coming directly from the brain. This greatly reduced line noise caused by movement or electrical artifact. The FET output was then voltage-amplified by low-noise, battery powered, solid state amplifiers (Brakel, Babb, Mahnke, \& Verzeano, 1971). Special D-ST Vetter amplifiers, designed for recording neural spike data, were used to record the amplified signals on magnetic tape.

\section{Sound Generation and Calibration}

The auditory stimulus was a 350 -msec burst of white noise generated by a Grason-Stadler Model 1285 noise generator, gated on and off by a Grason-Stadler Model 1287B electronic switch, set for a 10 -msec rise-fall time, attenuated by a Hewlett-Packard 350BR attenuator set, amplified by a Crown Model D-60 power amplifier, and transduced via an Electro-voice Model MR10 midrange hyperbolic horn. Stimulus presentation was controlled automatically using TTL digital logic circuits.

A white-noise conditioned stimulus (CS) was used here, in preference to the $1-\mathrm{kHz}$ pure tone we have employed in previous work on brain substrates of learning, to simplify neural recording from auditory brain structures. There is clear and multiple tonotopic selectivity of neuronal responses at all levels of the auditory system from the cochlear nucleus to the auditory cortex (Brugge \& Geisler, 1978; Erulkar, 1975; Evans, 1975; Goldberg, 1975; Goldstein, 1975; Webster \& Aitkin, 1975). A white noise will thus activate a much larger sample of neurons than will any pure tone, particularly at threshold-level intensities where auditory neuron tuning curves are narrowest. Certain auditory areas show little or no response to pure-tone stimulation but a marked response to white noise and other complex stimuli (Aitkin, Fryman, Blake, \& Webster, 1972; Erulkar, 1975; Goldstein, 1975; Irvine \& Huebner, 1979; Phillips \& Irvine, 1979). The problem of standing waves is also strongly reduced with a white-noise stimulus.

A free-field system was used instead of a closed system for several reasons. It was far less iraumatic for the animal, especially in comparison with preparations in which a probe is cemented in place. A less permanent probe was considered and decided against, because slight movements of a nonrigid closed system would have drastically changed its resonance properties, creating unwanted fluctuations in stimulus intensity.

Care was taken to maximize stimulus control. All the experiments were conducted in a large $(2 \times 2 \times 2 \mathrm{~m}$ i.d.), doublewalled, sound-attenuation chamber (Industrial Acoustic Company, Inc.). The rabbits were first severely restrained with their pinnae immobilized. The pinnae and the restrainer were then precisely positioned with respect to the horn and bolted in place so that the ear openings were always at the same distance $(9 \mathrm{~cm})$ and in the same orientation to the horn. In this final position, the pinnae were slightly twisted so that the external ear canals pointed upwards and were clearly open. The horn faced downwards in a line parallel with the line of the ear canals and was positioned sym- 
metrically with respect to the rabbit. The opening of the horn measured $24 \times 8 \mathrm{~cm}$ and was $9 \mathrm{~cm}$ from the ear openings, which were about $5 \mathrm{~cm}$ apart. Echoes were minimized by placing soundabsorbing material on nearby reflecting surfaces. The proximity of the acoustic horn-made reflections from more distant objects small in comparison with the signal itself.

Intensity measurements were made electronically with a HewlettPackard Model 302A wave analyzer and acoustically with a Brüel and Kjaer Type 2209 pulse precision sound-level meter, Type 4134 microphone, and Type 1613 octave filter set. The microphone was positioned in the empty apparatus midway between the positions that would later be occupied by the rabbit's ear openings. All measurements are made in reference to .0002 dynes $/ \mathrm{cm}^{2}$. Background levels were below the accuracy of the sound-level meter (i.e., below $25 \mathrm{~dB}$ using the octave filter set) in a range of 125 $31,500 \mathrm{~Hz}$. This range included the $1-16 \mathrm{kHz}$ range of the horn. To test the linearity of our system, frequency vs. intensity plots at several attenuations were made using the octave filter set. Attenuation was linear to within $1 \mathrm{~dB}$, and the spectrum was flat to within $5 \mathrm{~dB}$ in the range of the horn. Our training stimulus measured $78 \mathrm{~dB}$ using the $A$ filter network, and its spectral level, $\mathbf{N}_{\mathbf{o}}$ (sometimes called sound-pressure level per cycle), was calculated to be $36 \mathrm{~dB}$. Spectral level is used throughout this paper because psychophysical experiments have shown that it is the best measure of noise threshold (Green, 1976; Hirsh, 1952). Low-level stimuli were created by attenuating our $36-\mathrm{dB}$ training stimulus.

\section{Surgery and Recording Procedures}

Neuronal data reported here are limited to five animals with electrodes in the anteroventral cochlear nucleus. All electrode locations were verified histologically. Behavioral data from two of these animals were used in the behavioral threshold portion of the study as well. The remaining three animals were run to provide additional neuronal data. They were given identical training and testing, and their behavioral threshold results were similar to those of the other animals. Surgical procedures were similar to those previously reported (Berger \& Thompson, 1978; Cegavske, Patterson, \& Thompson, 1979). The animals were anesthetized with halothane, using a custom stereotaxic headholder which held the subject by the snout and eliminated the possibility of damage to the ears (Cegavske \& Biela, Note 1). The skull was exposed, and up to four Epoxolite-insulated stainless steel "multiple-unit" microelectrodes, with 5-7- $\mu \mathrm{m}$-diam tips and with $40-50 \mu \mathrm{m}$ of the shaft exposed, were chronically implanted in various areas of the brain. A combination of stereotaxic coordinates and electrophysiological cues (i.e., responses to acoustic stimuli) was used to place the electrodes. The electrodes were cemented to the skull using dental acrylic anchored to skull screws, and wires which had been soldered to the electrodes before implantation were soldered to an output plug. Another wire was soldered to a bone screw that served as a reference ground. For some experiments, a chronic microdrive for recording from single units was also cemented to the skull. This allowed us to lower finely etched, stainless steel microelectrodes with 3-5- $\mu \mathrm{m}$-diam tips and 300-500-k $\Omega$ tip resistances, before each experimental session. The output plug and a nut for bolting down a headstage were cemented to the skull. A topical antibiotic was then applied to the exposed skull, the wound was sutured closed, and an injection of bicillin was administered. Finally, a small loop of 6-0 nylon thread was sutured into the nictitating membrane (NM) so that the NM response could be recorded. All the animals were allowed to recover for at least 1 week prior to behavioral training.

After all training and testing procedures were completed, the animals were deeply anesthetized with pentobarbital and small electrolytic lesions $(100 \mu \mathrm{A}, 10 \mathrm{sec})$ were made through the recording electrodes with a constant current dc source. The animals were then perfused through the heart with $.9 \%$ saline followed by $10 \%$ Formalin. Verification of electrode placements was made with enlarged photographs and standard stains of frozen sections of the brain in conjunction with a Prussian blue reaction for iron deposit left from production of the lesion through the steel electrode tips.

\section{Data Analysis}

The data recorded on magnetic tapes were later played back for computer analysis. The recorded NM voltages were fed into an analog-to-digital converter, and the computer sampled this digitized signal every $3 \mathrm{msec}$ for a total of $2563-\mathrm{msec}$ periods each trial. These digitized NM records were then averaged together and further analyzed. For the averaged records, both the mean and the sum of squares were saved for each 3 -msec bin. The sum of squares was used in various statistical tests.

The NM averaged data were analyzed by the computer as follows: NM latency was defined to be the latency of the first of 30 consecutive bins showing a $.2-\mathrm{mm}$ increase above pre-CS baseline levels. The peak amplitude of the $\mathrm{NM}$ and the area under the NM curve were computed in relation to the mean of the pre-CS period. Measures of NM response variability were computed from the averaged records.

Recorded multiple-unit activity was bandpass filtered at $500 \mathrm{~Hz}$ to $5 \mathrm{kHz}$ by an electronic filter and then led to pulse height discriminators set to pass only the larger units. Our criteria for acceptable multiple-unit recording require: (1) that the individual neuron action potentials be clearly visible above the background noise level, (2) that the discriminator heights (pickoff levels) be set to count only units that are at least $50 \%$ higher in amplitude than the background noise level, and (3) that the "spontaneous" level of neuronal activity in the pre-CS period be kept less than $100 \mathrm{spikes} / \mathrm{sec}$. Our intent was to record from no more than five or six of the larger units. Often we did much better. The number of pulses leaving the discriminator was continuously monitored by the computer, and these counts were stored every $3 \mathrm{msec}$ in 256 3-msec bins. These histograms were then averaged together for final analysis. Both the mean and the sum of squares were saved for all 256 bins that were averaged.

Single-unit activity was processed in a similar way. A single unit was characterized by both its magnitude and its firing pattern. It was analyzed only if it was clearly isolated from other units and the background noise levels.

Behavioral detect and nondetect trials (as defined in the training section) were averaged separately as follows. For each threshold session, an equal number of detect and nondetect trials were chosen randomly at each intensity level. Having selected trials in this counterbalanced way, detect trials obtained from several sessions and at several threshold intensities were averaged together to form NM and neuronal response averages for the detect trials. Nondetect trials were averaged together in a similar way. Because there was a balanced number of detect and nondetect trials from each session, slight variations in stimulus intensity from session to session are not important. At threshold, only CS-alone trials were averaged for ease in interpretation. Any observed response was due to the white-noise CS and not the airpuff US.

ROC curves were constructed for the cochlear nucleus response during both detect and nondetect performance. For this purpose, noise and signal were defined as the 100 -msec periods immediately before and after auditory onset, respectively. The signal detection response criterion (using a fixed neuronal spike amplitude discriminator level) was then systematically varied from 0 spikes $/ \mathrm{sec}$ to the maximal response rate observed, and likelihood ratios were calculated. These ratios were then ordered and used to make a standard ROC plot (Green \& Swets, 1966). ${ }^{1}$

\section{RESULTS}

\section{Behavioral Training}

The animals $(N=13)$ reached learning criterion (eight of nine CRs) in a mean of 1.2 sessions, reached 
learning asymptote in a mean of 5.5 sessions, and reached threshold levels in a mean of 8.2 sessions. Figure 1 depicts the percentage of CRs and the percentage of spontaneous NM movements (in pre-CS periods) during each quarter session. There is a sharp increase in the percentage of CRs between the last quarter of Day 1 and the first quarter of Day 2, which coincides with reaching learning criterion. Asymptotic levels are above $90 \%$, although we required only $80 \%$. At threshold, there is a drop to about $50 \%$ conditioned responding, as required by the 50\% definition of threshold. There is also a tendency toward higher $C R$ rates in the first quarter of each threshold session. This results from starting the animals $6 \mathrm{~dB}$ above the previous day's threshold. Spontaneous NM movements are all below $10 \%$ and remain constant within each session and also across training sessions.

\section{Threshold Levels Obtained}

The mean threshold for our white-noise stimulus was $-11.7 \mathrm{~dB}$ spectral level (see Methods for more detail). Thresholds were markedly different from animal to animal, the cross-animal standard deviation being $15.3 \mathrm{~dB}$. Within an animal, however, thresholds were extremely stable from session to session, the average within-animal standard deviation being only $2.4 \mathrm{~dB}$. Figure $2 \mathrm{~A}$ shows the average lowest intensity used during each session. The decrease in intensity is initially linear because the animals made few mistakes after learning to asymptote and before threshold levels. They were dropped a maximum of $10 \mathrm{~dB}$ each session until threshold levels were reached.

Figure 2B illustrates the mean $(\mathrm{N}=12)$ threshold during each session, starting with the first session upon which threshold levels were obtained. The mean threshold obtained during the initial threshold session was $-7 \mathrm{~dB}$ and during the final session, $-15 \mathrm{~dB}$, a statistically significant difference $[\mathrm{t}(11)=-5.8$, $\mathrm{p}<.001]$. The largest drop occurred after the first day of threshold-level behavior, a significant decrease of $-3.5 \mathrm{~dB}[\mathrm{t}(11)=-2.5, \mathrm{p}<.05]$. Other changes from session to session were less than $2 \mathrm{~dB}$ and were not statistically significant. We have excluded the initial threshold measure from our calculations of mean threshold. As can be seen in Figure $2 \mathrm{~B}$, threshold behavior was reasonably stable by the second threshold session.

\section{NM Response Properties}

Figure 3 shows the averaged NM response of a typical animal at various stages of training and at threshold. The top pair of graphs show the averaged NM response before learning (i.e., before the animal began to give CRs) for CS-US paired trials and CSalone trials, respectively. The arrows indicate CS and US onsets. The middle pair of graphs depict the averaged NM response at learning asymptote, again for CS-US paired and CS-alone trials, respectively. The bottom pair of graphs show detect and nondetect NM responses at behavioral threshold. At threshold levels, the NM response increases in latency and decreases in size. There is a sharp, all-ornone contrast between detect and nondetect averages, although we define detection as more than $.5 \mathrm{~mm}$ of NM movement and nondetect as less than $.5 \mathrm{~mm}$ of NM movement, that is, as a continuous variable.

The behavioral NM response was characterized by four measures: NM onset latency, NM peak latency, NM peak amplitude, and NM area (Berger \& Thomp-

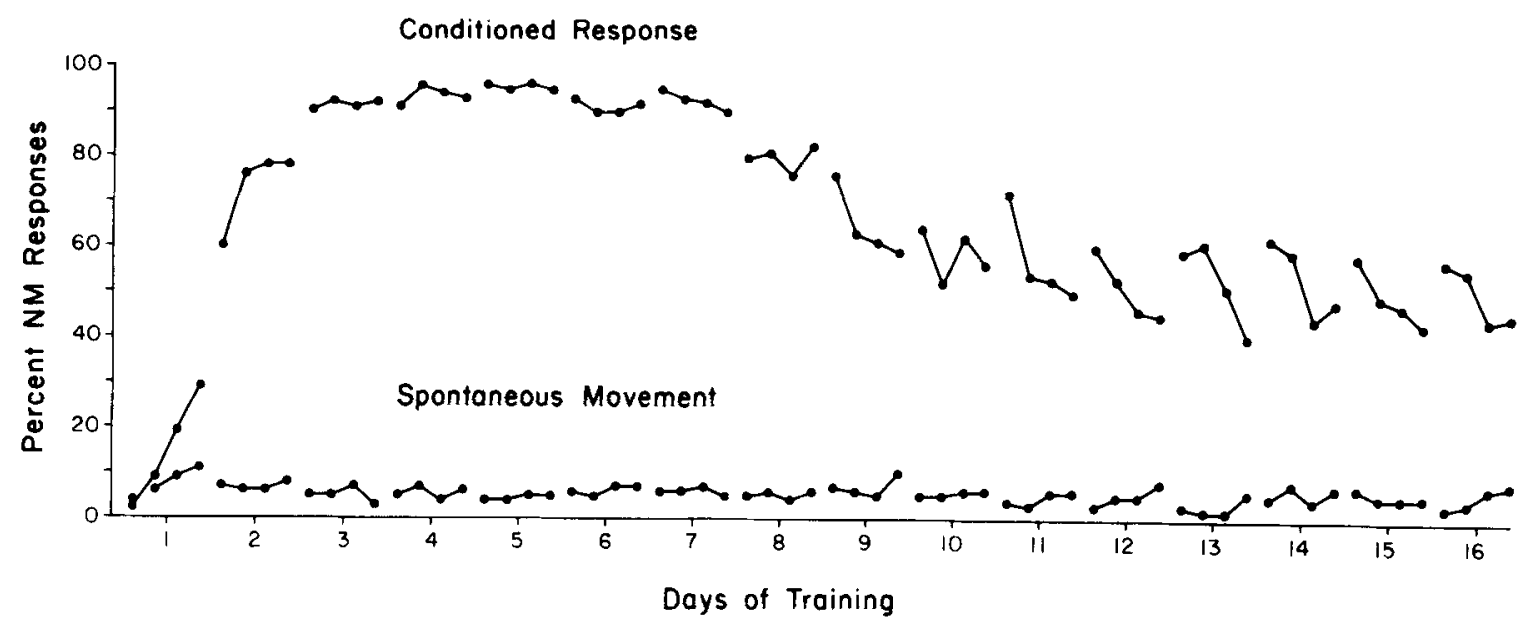

Figure 1. Percent nictitating membrane (NM) responses over training and testing. The upper line depicts the average $(N=13)$ percent conditioned responses for each quarter of each daily training session. The lower line depicts the percentage of spontaneous movements (i.e., false alarms) in each of these periods. 


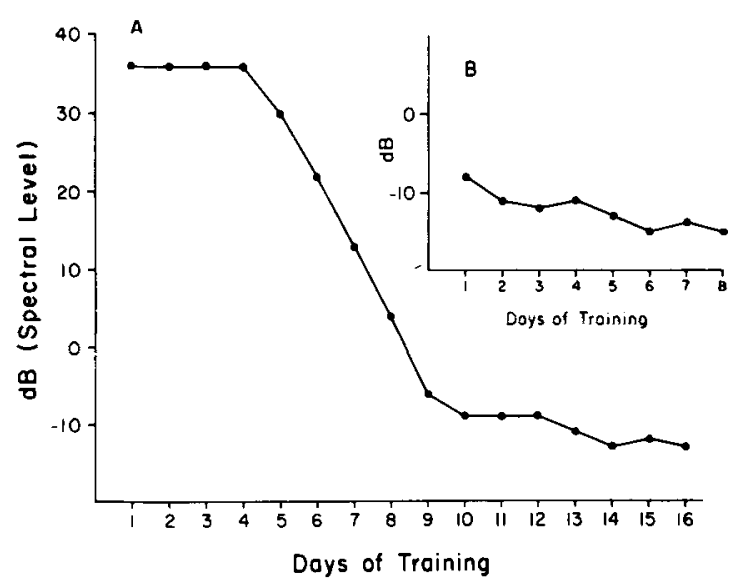

Figure 2. Conditioned stimulus (CS) intensity during training. Part A shows the average $(N=13)$ decine in the intensity of the white-noise CS over the course of training. Part B shows the average $(N=12)$ threshold for each session beginning with the first session in which threshold levels were obtained. Spectral level is used to measure intensity.
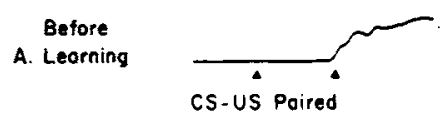

Learning
B. Asymptote

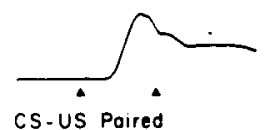

C. Threshold

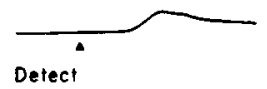

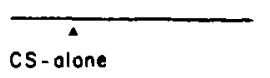

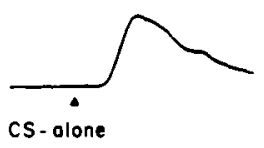

Non-detect
Figure 3. Nictitating membrane (NM) topography changes during training. In each case, the duration of the horizontal response line marks time from 0 to 750 msec. Movement of the NM is in the vertical direction. Arrows are placed at CS and US onsets. Part A shows average NM topographies for an animal before learning criterion had been reached for both CS-US paired trials and CS-alone trials. Part B shows analogous averages for the same animal after learning had reached asymptote. Part $C$ shows NM topographies at threshold for both behavioral detect and nondetect conditions. In this case, only CS-alone averages of 258 trials are shown. Notice the dichotomous nature of the threshold responses.

son, 1978; Cegavske et al., 1979). Each measure was averaged across all animals $(\mathbf{N}=13)$ at learning asymptote, and at 4,2 , and $0 \mathrm{~dB}$ above behavioral threshold for CS-alone trials (see Table 1). There was a statistically significant change in all four NM quantities as the $\mathrm{CS}$ intensity was reduced to threshold $[\mathrm{t}(12)=-7.6, \mathrm{p}<.001 ; \mathrm{t}(12)=-2.8, \mathrm{p}<.01$; $\mathrm{t}(12)=6.3, \mathrm{p}<.001 ; \mathrm{t}(12)=6.2, \mathrm{p}<.001$, respectively, for onset latency, peak latency, amplitude, and area]. Both measures of latency significantly increased at behavioral threshold, and both measures of NM magnitude significantly decreased at behavioral threshold.

At threshold levels, only onset latency showed significant increases as CS intensity dropped from $4 \mathrm{~dB}$ above threshold to $2 \mathrm{~dB}$ above threshold [t(12) = $-3.1, p<.005$ ] and then from $2 \mathrm{~dB}$ above threshold to threshold $[\mathrm{t}(12)=-1.8, \mathrm{p}<.05]$. Peak latency was roughly twice as variable and showed no significant changes at threshold levels. Both NM amplitude and NM area were nearly constant at threshold levels. The stability of the amplitude measures is consistent with the all-or-none character of behavioral detection averages at threshold (see Figure 3). In terms of statistically significant variation with stimulus intensity at threshold, onset latency of the NM response seems clearly to be the most sensitive measure of threshold behavior.

Changes in the four NM measures with CS intensity are illustrated in Figure 4. It consists of mean data from three animals with nearly identical thresholds of approximately $-24 \mathrm{~dB}$ spectral level. As for the above averages based on all animals $(\mathrm{N}=13)$, all four quantities are near constant and then change dramatically at threshold. At threshold levels, latency measures continue to increase, while magnitude measures are fairly constant.

\section{Neurophysiological Results}

Data from "multiple-unit" electrodes placed in the anteroventral cochlear nuclei (AVCN) of five animals are reported here. Figure 5 shows average poststimulus histograms from an individual animal constructed from 174 detect and an equal number of nondetect trials collected from six threshold sessions. Unit counts were tallied in 3-msec bins starting $201 \mathrm{msec}$ before CS-onset and continuing for $554 \mathrm{msec}$ after CS-onset. Counts are displayed in 15 -msec bins. The arrow indicates onset of the whitenoise CS. Qualitatively, both detect and nondetect responses resemble the primarylike responses of

Table 1

Average $(\mathrm{N}=13)$ NM Parametric Changes With CS Intensity

\begin{tabular}{ccccc}
\hline \multirow{2}{*}{$\begin{array}{c}\text { Decibels } \\
\text { Above } \\
\text { Threshold }\end{array}$} & $\begin{array}{c}\text { Onset } \\
\text { Latency }\end{array}$ & $\begin{array}{c}\text { Peak } \\
\text { Latency }\end{array}$ & $\begin{array}{c}\text { Peak } \\
\text { Amplitude }\end{array}$ & Area \\
\hline LA & 317 & 431 & 4.7 & 1012 \\
4 & $367^{*}$ & $468^{*}$ & $1.4^{*}$ & $319^{*}$ \\
2 & $380^{*}$ & 494 & 1.5 & 339 \\
0 & $388^{+}$ & 491 & 1.4 & 305 \\
\hline
\end{tabular}

Note-Latencies are given in milliseconds; amplitude is given in millimeters; area is given in $m m$-msec. $L A=$ learning asymptote. $t$ statistics were used to evaluate the change of a given value from the value immediately above it.

${ }^{*} p<.05 . \quad \dagger p<.01$. 

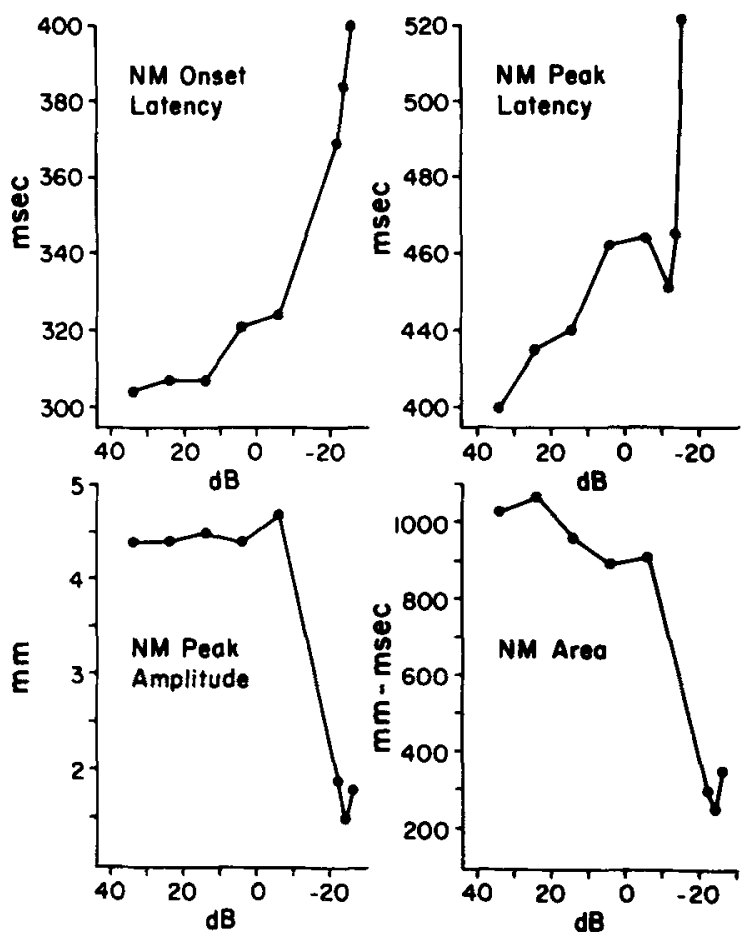

Figure 4. Nictitating membrane (NM) parameter changes with sound intensity. Three animals with nearly identical thresholds near $-24 \mathrm{~dB}$ were averaged here, but animals with other thresholds showed similar results. Notice the parallel increase in onset and peak latencies, and the decrease in peak amplitude and area. These changes were strongest near threshold.

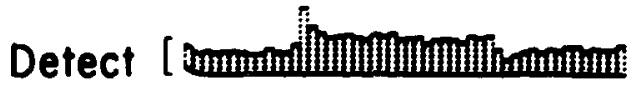 \\ $\Delta$}

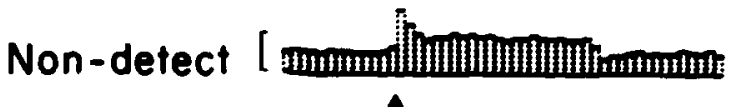

Figure 5. Anteroventral cochlear nucleus neural unit response histograms at auditory threshold. Detect and nondetect multipleunit histograms for a typical animal are shown. Each is the average of 174 trials. Histograms resemble primary-like histograms obtained from single units in the anteroventral cochlear nucleus, and are essentially identical for detect and nondetect trials. Histograms show 750 msec of activity in $15-\mathrm{msec}$ bins. The vertical calibration indicates a rate of 100 spikes/sec. Arrows indicate the onset of the white-noise CS.

single units found in the AVCN (Evans, 1975; Kiang, Pfeiffer, Warr, \& Backus, 1965; Pfeiffer, 1966). Indeed, these "multiple-unit" histograms are qualitatively identical to histograms of single-neuron responses in the AVCN.

To evaluate possible response differences between detect and nondetect responses, the mean and stan- dard deviation for the last $100 \mathrm{msec}$ of the pre-CS period and the first $100 \mathrm{msec}$ of the CS period for both detect and nondetect response averages were calculated for all five animals. The results are summarized in Table 2. Both detect and nondetect values and ratios between these detect and nondetect measures are displayed. Detect and nondetect values were compared statistically using that statistic. On the average, the pre-CS mean was $9 \%$ greater on nondetect trials and CS mean was $5 \%$ greater on nondetect trials. The difference between pre-CS and CS means was $2 \%$ greater on detect trials, and the signalto-noise ratio was $5 \%$ greater on detect trials. With few exceptions, these differences were not statistically significant. For those exceptions, both the pre-CS and the CS means were significantly greater on nondetect trials.

ROC curves (Green \& Swets, 1966) were constructed for the cochlear nucleus response for both detect and nondetect performance with similar results. Detect ROC curves were virtually identical to nondetect ROC curves. A typical result is displayed in Figure 6. The lack of any response would be indicated by points along the diagonal. The proportion of area under each ROC curve was also calculated (see Table 2). This proportion is a distribution-free measure of detectability which corresponds to the percentage correct in a two-alternative forced-choice procedure (Green \& Swets, 1966). On the average $(\mathrm{N}=5)$, values of $77.2 \%$ and $78.5 \%$ were obtained for detect and nondetect curves, respectively. Again, these values are essentially identical.

To demonstrate that multiple-unit measures are sensitive correlates of CS intensity at threshold, we have plotted anteroventral cochlear nucleus responses at various $C S$ intensities for a typical animal. Figure 7 shows the CS means, the pre-CS means, and the pre-CS vs. CS period differences for both detect and nondetect averages at four threshold-level intensities in 2-dB steps. On both detect and nondetect trials, the CS mean monotonically decreases until pre-CS levels are reached, the pre-CS mean is relatively constant, and their difference decreases monotonically. Comparing detect against nondetect averages, CS period and pre-CS period response rates are generally greater on nondetect trials, but their differences were usually almost equal.

To show the usefulness of our preparation in evaluating models of signal detection, we have directly calculated the probability distributions associated with neuronal responding under both "noise-alone" (i.e., pre-CS period) and "signal-plus-noise" (CS period) conditions for a typical animal in Figure 8. Each distribution was constructed from either 30 pre-CS means or $30 \mathrm{CS}$ means obtained at one of five CS intensities near threshold. The horizontal dimension is response rate rounded to the nearest 10 counts/sec, and the vertical dimension is the number of means at each 
Table 2

\begin{tabular}{|c|c|c|c|c|c|c|c|c|c|c|c|c|c|c|c|}
\hline \multirow[b]{3}{*}{ Animal } & \multicolumn{10}{|c|}{ Cochlear Nucleus Response Values } & \multicolumn{5}{|c|}{ Ratio Between D and N Means } \\
\hline & \multicolumn{2}{|c|}{ PreCS Mean } & \multicolumn{2}{|c|}{ CS Mean } & \multicolumn{2}{|c|}{ Difference } & \multicolumn{2}{|c|}{ Ratio } & \multicolumn{2}{|c|}{ ROC Area } & \multirow{2}{*}{$\begin{array}{l}\text { PreCS } \\
\text { Mean }\end{array}$} & \multirow{2}{*}{$\begin{array}{c}\text { CS } \\
\text { Mean }\end{array}$} & \multirow{2}{*}{$\begin{array}{c}\text { Differ- } \\
\text { ence }\end{array}$} & \multirow{2}{*}{ Ratio } & \multirow{2}{*}{$\begin{array}{l}\text { ROC } \\
\text { Area }\end{array}$} \\
\hline & $\mathrm{D}$ & $\mathrm{N}$ & $\mathrm{D}$ & $\mathrm{N}$ & $\mathrm{D}$ & $\mathrm{N}$ & $\mathrm{D}$ & $\mathrm{N}$ & D & $\mathrm{N}$ & & & & & \\
\hline $78-50$ & 71.2 & 73.3 & 139.2 & 140.5 & 68.1 & 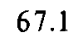 & 1.96 & 1.92 & .885 & .88 & .97 & .99 & 1.01 & 1.02 & 1.00 \\
\hline $78-59$ & & 85.2 & 131.3 & 127 & 46. & 42. & 1.55 & 1.50 & .692 & .712 & 1.00 & 1.03 & 1. & 1.03 & .97 \\
\hline $78-572$ & & 69.4 & 93.0 & 95 & 26. & 26. & & 1.2 & .74 & .75 & .95 & .97 & 1.03 & & .99 \\
\hline $79-459$ & 35.2 & 40.5 & 60.5 & 66.4 & 25.2 & 25.9 & 1.72 & 1.64 & .717 & .783 & $.87 *$ & $.91^{*}$ & .97 & 1.05 & .92 \\
\hline $79-477$ & 65.3 & 87.1 & 133.5 & 155.8 & 68.7 & 58.7 & 2.04 & 1.79 & .828 & .801 & $.75^{*}$ & $.86^{*}$ & .99 & 1.14 & 1.03 \\
\hline Mean & & & & & & & & & & & .91 & .95 & 1.02 & 1.05 & .98 \\
\hline
\end{tabular}

Note $-D=$ detect $; N=$ nondetect. $\quad{ }^{*} p<.01$.

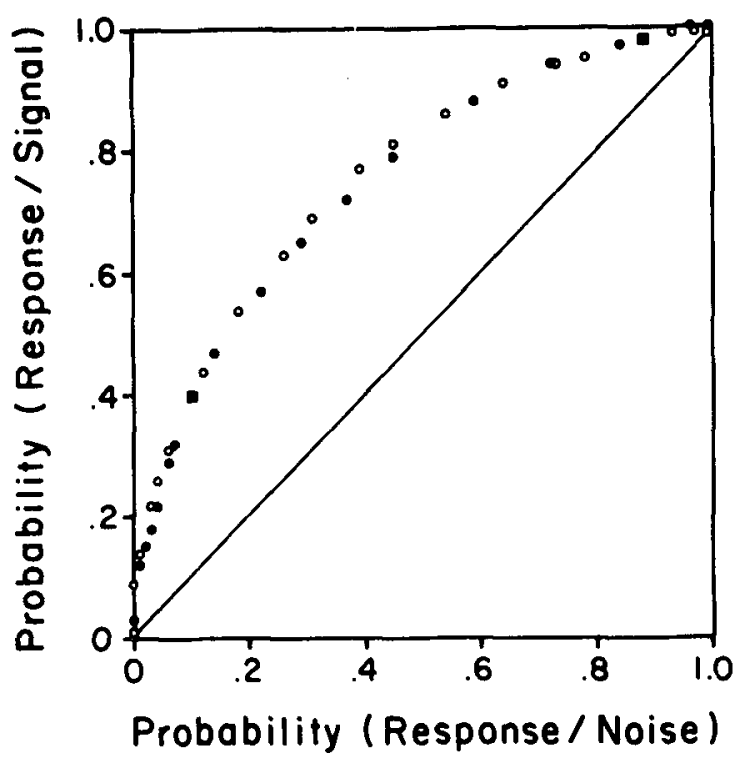

Figure 6. ROC curves of the cochlear nucleus response at behavioral threshold on detect and nondetect trials for a typical animal. Solid circles correspond to detect responses and open circles correspond to nondetect responses; solid squares indicate the overlap of solid and open circles. The diagonal indicates chance performance. Notice that these two sets of points lie on virtually the same curve, indicating that detect and nondetect responses in the cochlear nucleus are identical.
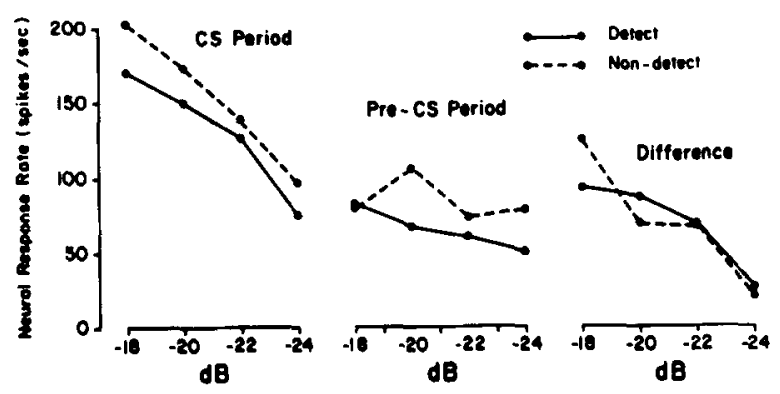

Figure 7. Cochlear neural-unit response parameters at several threshold-level intensities for detect and nondetect values. Mean firing rates for the CS and pre-CS periods at four threshold-level intensities are illustrated in the left and center two graphs. The right graph was created by subtracting CS period means from preCS period means and shows the increase in firing due to the whitenoise stimulus. Solid lines indicate detect averages and broken lines indicate nondetect averages for a typical animal. Each line is constructed from a total of 174 trials. particular response rate. Stimulus intensities are in decibel spectral level.

Starting at the top, the noise-alone distribution and the signal-plus-noise distribution are clearly separated at $-4 \mathrm{~dB}$. They begin to merge at $-14 \mathrm{~dB}$, and overlap still more at $-24 \mathrm{~dB}$, although the mean of the signal-plus-noise distribution (the black squares) is clearly greater than the mean of the noise-alone distribution (the white squares) at $-24 \mathrm{~dB}$. The lowest behavioral threshold level obtained for this animal was $-24 \mathrm{~dB}$. At $-34 \mathrm{~dB}$, the two distributions can still be distinguished, but they overlap considerably. Overlap appears to be complete at $-44 \mathrm{~dB}$.

Also, $t$ values were calculated at each intensity, with similar results. At $-24 \mathrm{~dB}$, the difference between the mean of the signal-plus-noise and the mean of the noise-alone distributions was just above the $\mathrm{p}<.05$ confidence level $[\mathrm{t}(58)=1.5, \mathrm{p}=.065]$ Above $-24 \mathrm{~dB}$, the differences were clearly significant $[\mathrm{t}(58)>6.3, \mathrm{p}<.001]$. Below $-24 \mathrm{~dB}$, the differences were clearly nonsignificant $[\mathrm{t}(58)>.2, \mathrm{p}>.4]$.

\section{DISCUSSION}

The results of these experiments indicate that the rabbit nictitating membrane (NM) preparation is well suited for the study of signal detection behavior and its neurophysiological correlates. A standardized procedure for training rabbits to perform at auditory threshold has been described in detail. This training schedule utilizes a staircase (or tracking) procedure that asymptotes at a 50-50 ratio of detect and nondetect trials, the optimal ratio for statistically comparing detect and nondetect trials. For a given animal, threshold levels are very stable from day to day. After the first threshold level session, thresholds are almost constant $(\mathrm{SD}=2.4 \mathrm{~dB})$, making across-day comparisons and averaging possible. False-alarm rates are generally below $10 \%$ and are constant across days and within days.

A close similarity between human and rabbit thresholds also argues that the rabbit preparation is a good animal system for studies of human signal detection. Human thresholds for a comparable 350msec white-noise burst are $-21 \mathrm{~dB}$ spectral level 


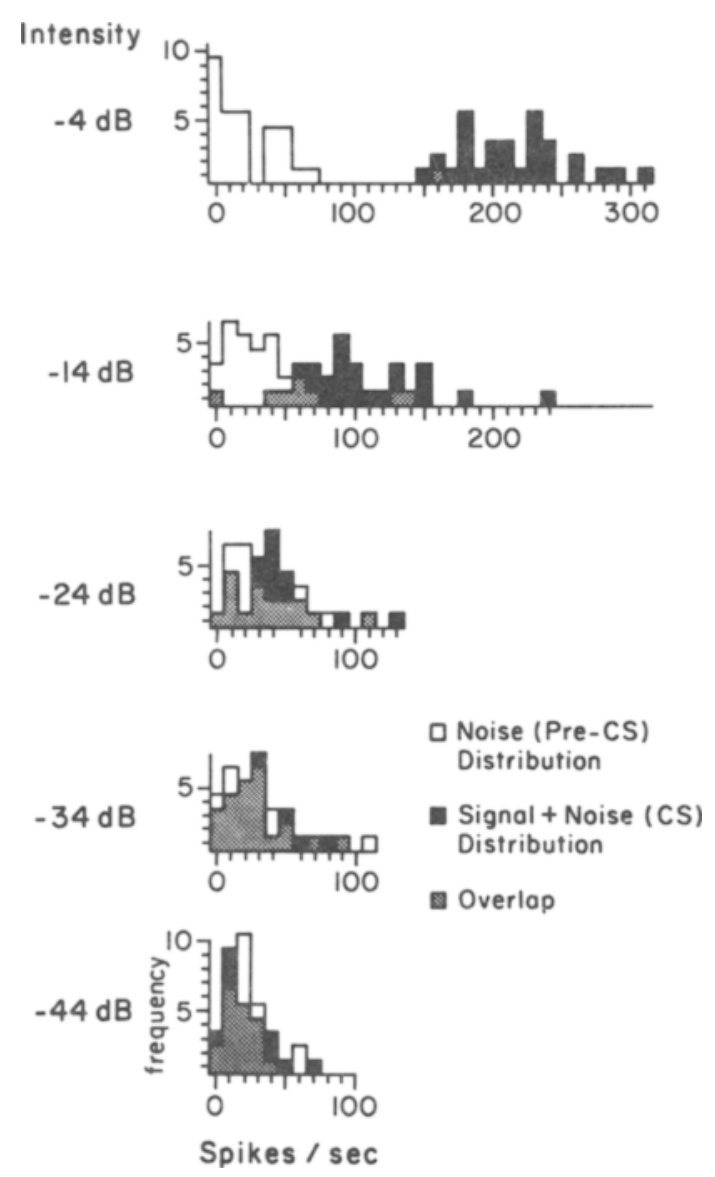

Figure 8. Signal-plus-noise and noise-glone frequency distributions of neural-unit activity at several near-threshold intensities for a typical animal. Solid bars indicate the signal-plus-noise (CS) distribution, white bars indicate the noise-alone (pre-CS) distribution, and dotted bars indicate an overlap of distributions. The distributions begin to merge at $-24 \mathrm{~dB}$, the behavioral threshold for this animal.

(Miller, 1948). This value is within one standard deviation of the $-11.7 \mathrm{~dB}(\mathrm{SD}=15.3 \mathrm{~dB})$ mean spectral level threshold obtained for all rabbits $(\mathrm{N}=13)$ and is nearly identical to the $-22.3 \mathrm{~dB}(\mathrm{SD}=4.6 \mathrm{~dB})$ mean spectral level threshold obtained for our best rabbits $(\mathrm{N}=8)$.

The NM response itself is readily quantifiable and both NM magnitude and latency covary with stimulus intensity. Changes in magnitude and latency are most pronounced at threshold levels; NM magnitude decreases significantly and NM latency increases significantly at threshold. Onset latency appears to be the most sensitive measure of threshold behavior, suggesting that it will be a useful indicator for neurophysiological studies of psychophysical reaction time tasks.

The NM response has a dichotomous character, even though our operational definition of behavioral detection, NM movement greater than $.5 \mathrm{~mm}$, was continuous. The NM response was present in behav- ioral detect averages, but nonexistent for behavioral nondetect averages. This makes our NM measure similar to the all-or-none measure of pressing a telegraph key, another similarity between the rabbit NM preparation and experiments using humans. The dichotomous nature of the averaged behavioral response also suggests that a "decision" is made at some level of the nervous system which determines whether a signal is present or not. Below, we suggest that this decision has not been made by the time auditory information reaches the anteroventral cochlear nucleus.

Recordings from the anteroventral cochlear nuclei of five behaving animals showed essentially no difference in detect vs. nondetect neuronal response averages at behavioral threshold. Each comparison is based on at least 10,000 data points. These results are in sharp contrast to the dichotomous character of the averaged behavioral NM response. To the extent that the anteroventral cochlear nucleus responds identically on both detect and nondetect trials, it may be argued that the acoustic stimuli, middle-ear muscle contractions, cochlear responses, and eighth nerve responses are all identical under both detect and nondetect conditions. The "decision" of detection or nondetection must be made at a more central locus in the brain.

ROC curves were also used to characterize the cochlear nucleus response during both detect and nondetect performance. ROC areas were calculated. The results again demonstrated that the cochlear nucleus response is essentially identical on detect and nondetect trials. The ROC curve characterizes the detection performance of a mathematically ideal observer (Green \& Swet, 1966). Thus, identical ROC curves on both detect and nondetect trials indicate that a mathematically ideal observer would find no difference between the detect and the nondetect cochlear nucleus response. These ROC curves also indicate that an ideal observer would do much better than chance $(50 \%)$ detection. In both detect and nondetect conditions, the ROC area would predict an average of nearly $80 \%$ correct detection performance in a two-alternative forced-choice procedure. Our animals were, in fact, detecting behaviorally at the $50 \%$ level.

It could be argued that the lack of a difference in the anteroventral cochlear nucleus responses on detect and nondetect trials is the result of recording from a flat region on the intensity curve of the unit response. For this reason, changes in cochlear response rate to the $2-\mathrm{dB}$ changes in intensity at threshold levels were examined. In each case, cochlear response rate was a monotonically increasing function of stimulus intensity at threshold (see Figure 7).

Another area of caution concerns the fact that our sample of neuronal activity from the cochlear nucleus is limited to five electrode placements. Ana- 
tomically, the distribution of electrode tips was restricted to the anteroventral cochlear nucleus (AVCN). Two animals (the last two in Table 2) had placements near the anterior tip of the AVCN. The other three animals had placements more posterior in the AVCN and closer to the bifurcating cochlear nerve. It could also be argued that single-unit recording might reveal at least some neurons that respond differentially on detect and nondetect trials. We would suggest that in the present experimental context, multiple-unit recording may well provide a more meaningful sample of the behavior of the population of neurons in the anteroventral cochlear nucleus. Certainly, the poststimulus histograms of multiple-unit activity in the present study appear to be identical in every way to poststimulus histograms of the activity of single neurons recorded from this structure. However, single-unit recording must also be done in the present experimental context. Indeed, in very preliminary single-neuron recordings from the anteroventral cochlear nucleus, we have obtained results identical to the multiple-unit data reported here. In any event, our data do suggest an essentially identical neuronal response in the anteroventral cochlear nucleus for behavioral detection and nondetection trials.

The use of this preparation to explore models of signal detection which assume a neurophysiological base was illustrated in Figure 8. The actual probability distributions for both signal-plus-noise (the CS period) and noise-alone (the pre-CS period) conditions were directly calculated. A close correspondence between one animal's behavioral threshold and the overlap of the calculated distributions was found. This relation holds as well for the other four electrode placements.

In summary, we have detailed a technique for studying the neurophysiological basis of signal detection behavior. Stimulus control is excellent and middle ear muscle variation appears to be minimal. It also appears that the detection "decision" is made either more centrally than the anteroventral cochlear nucleus or in some other area of the cochlear nucleus.

\section{REFERENCE NOTE}

1. Cegavske, C. F., \& Biela, J. A. A rabbit headholder for stereotaxic use with gaseous anesthetics. Manuscript in preparation.

\section{REFERENCES}

Aitkin, L. M., Fryman, S., Blake, D. W., \& Webeter, W. R. Responses of neurones in the rabbit inferior colliculus. I. Frequency-specificity and topographic arrangement. Brain Research, 1972, 47, 77-90.

Brakel, S., Babb, T., Mahnke, J., \& Verzeano, M. A compact amplifier for extracellular recording. Physiology \& Behavior, 1971, 6, 731-733.
Berger, T. W., \& Thompson, R. F. Neuronal plasticity in the limbic system during classical conditioning of the rabbit nictitating membrane response. 1. The hippocampus. Brain Research, 1978, 145, 323-346.

Brugge, J. F., \& Geisler, C. D. Auditory mechanisms of the lower brainstem. Annual Review of Neuroscience, 1978, 1, 363-394.

Cegavske, C. F., Patterson, M. M., \& Thompson, R. F. Neuronal unit activity in the abducens nucleus during classical conditioning of the nictitating membrane response in the rabbit, Oryctolagus cuniculus. Journal of Comparative \& Physiological Psychology, 1979, 93, 595-609.

ConNsweET, T. N. The staircase method in psychophysics. American Journal of Psychology, 1962, 75, 485-491.

Erulkar, S. D. Physiological studies of the inferior colliculus and medial geniculate complex. In W. D. Keidel \& W. D. Neff (Eds.), Handbook of sensory physiology (Vol, V/2). New York: Academic Press, 1975.

Evans, E. F. Cochlear nerve and cochlear nucleus. In W. D. Keidel \& W. D. Neff (Eds.), Handbook of sensory physiology (Vol. V/2). New York: Academic Press, 1975.

Goldberg, J. M. Physiological studies of auditory nuclei of the pons. In W. D. Keidel \& W. D. Neff (Eds.), Handbook of sensory physiology (Vol. V/2). New York: Academic Press, 1975.

Goldstein, M. H. Single unit activity of the auditory cortex. In W. D. Keidel \& W. D. Neff (Eds.), Handbook of sensory physiology (Vol. V/2). New York: Academic Press, 1975.

Gormezano, I. Classical conditioning. In J. B. Sidowski (Ed.), Experimental methods and instrumentation in psychology. New York: McGraw-Hill, 1966.

Gormezano, I. Investigations of defense and reward conditioning in the rabbit. In A. H. Black \& W. F. Prokasy (Eds.), Classical conditioning II: Current research and theory. New York: Appleton-Century-Crofts, 1972.

Gormezano, I., Schneiderman, N., Deaux, E., \& Fuentes, I. Nictitating membrane: Classical conditioning and extinction in the albino rabbit. Science, 1962, 138, 33-34.

Green, D. M. An introduction to hearing. Hillsdale, N.J: Earlbaum, 1976.

Green, D. M., \& Luce, R. D. Counting and timing mechanisms in auditory discrimination and reaction time. In D. H. Krantz, R. C. Atkinson, R. D. Luce, \& P. Suppes (Eds.), Contemporary developments in mathematical psychology (Vol. 2) Measurements, psychophysics, and neural information processing. San Francisco: Freeman, 1974.

Green, D. M., \& Swets, J. A. Signal detection theory and psychophysics. New York: Wiley, 1966.

Hirsh, I. J. The measurement of hearing. New York: McGrawHill, 1952.

Invine, D. R. F., \& Huebner, H. Acoustic response characteristics of neurons in nonspecific areas of cat cerebral cortex. Journal of Neurophysiology, 1979, 42, 107-122.

Kiang, N. Y. S., Pfeiffer, R. R., Warr, W. B., \& Backus, A. S. N. Stimulus coding in the cochlear nucleus. Annals of Otology, Rhinology and Laryngology, 1965, 74, 463-485.

LEvitT, H. Transformed up-down methods in psychoacoustics. Journal of the Acoustical Society of America, 1971, 49, 467-477.

Luce, R. D., \& Green, D. M. A neural timing theory for response times and the psychophysics of intensity. Psychological Review, 1972, 79, 14-57.

Luce, R. D., \& Green, D. M. Two tests of a neural attention hypothesis for auditory psychophysics. Perception \& Psychophysics, 1978, 23, 363-371.

McGILL, W. J. Neural counting mechanisms and energy detection in audition. Journal of Mathematical Psychology, 1967, 4, 351-376.

Miller, G. A. The perception of short bursts of noise. Journal of the Acoustical Society of A merica, 1948, 20, 160-170. 
Pfeiffer, R. R. Classification of response patterns of spike discharges for units in the cochlear nucleus: Tone-burst stimulation. Experimental Brain Research, 1966, 1, 220-235.

Phillips, D. P., \& Invine, D. R. F. Acoustic input to single neurons in pulvinar-posterior complex of cat thalamus. Journal of Neurophysiology, 1979, 42, 123-136.

Shevel, S. K. Similar threshold functions for contrasting neural signal models. Journal of Mathematical Psychology, 1979, 19, 1-17.

SwETs, J. A. Signal detection and recognition by human observers. New York: Wiley, 1964.

Thompson, R. F., Berger, T. W., Cegavske, C. F., Patterson, M. M., Roemer, R. A., Teyler, T. J., \& Young, R. A. The search for the engram. American Psychologist, 1976, 31, $209-227$.

WANDELl, B. A. On the analysis of nerve signals deduced from metacontrast experiments with human observers. Journal of Physiology (London), 1976, 263, 321-329.

Webster, W. R., \& Aitkin, L. M. Central auditory processing. in M. S. Gazzaniga \& C. Blakemore (Eds.), Handbook of psuchobiology. New York: Academic Press, 1975.

\section{NOTE}

1. We are indebted to David Green of Harvard University for suggesting this method of analysis.

(Received for publication June 24, 1980; accepted August 30, 1980.) 